\title{
Meropenem Assessment before and after Implementation of a Small-Dose, Short-Interval Standard Dosing Regimen
}

\author{
Ivy Chow, Vincent Mabasa, and Connor Chan
}

\begin{abstract}
Background: Small-dose, short-interval dosing for meropenem has been shown to yield pharmacokinetic and pharmacodynamic properties similar to those associated with traditional dosing of this drug. However, few studies have examined clinical outcomes in the general population.

Objectives: To characterize differences in effects between a small-dose, short-interval dosing regimen for meropenem $(500 \mathrm{mg}$ every $6 \mathrm{~h}$ ) and the traditional regimen (1000 mg every $8 \mathrm{~h}$ ) on clinical outcomes and costs to the health care system.

Methods: This retrospective cohort study included 194 patients who received the traditional meropenem dosage (July 2006 to August 2008) and 188 patients who received the small-dose, short-interval regimen (December 2008 and October 2009) at a large tertiary care hospital and a community hospital. The primary outcome (clinical success), the secondary outcomes (30-day in-hospital mortality, time to defervescence, duration of therapy, and length of stay), and drug costs were compared between cohorts.

Results: The 2 cohorts did not differ significantly in terms of baseline characteristics. There was no statistically significant difference between the small-dose, short-interval regimen and the traditional dosing regimen in terms of the primary outcome: clinical success was achieved in $83.5 \%$ $(162 / 194)$ and $80.8 \%(152 / 188)$ of the patients, respectively. Likewise, there was no statistically significant difference in any of the secondary outcomes. The average drug cost per patient per visit was $\$ 222.23$ with small-dose, short-interval dosing and $\$ 355.90$ with traditional dosing, a significant difference of more than $\$ 130$ per patient per visit.
\end{abstract}

Conclusion: The small-dose, short-interval meropenem dosing regimen resulted in clinical outcomes similar to those achieved with the traditional dosing regimen at significantly lower cost.

Keywords: meropenem, pharmacodynamics, stewardship, dosing, outcomes

Can J Hosp Pharm. 2018;71(1):14-21

\begin{abstract}
RÉSUMÉ
Contexte : Selon des études, un schéma posologique de méropénème avec administration d'une faible dose à intervalle réduit produit des résultats pharmacocinétiques et pharmacodynamiques semblables à ceux obtenus avec une posologie traditionnelle. Mais peu d'études ont examiné les résultats cliniques dans la population générale.
\end{abstract}

Objectif : Offrir un portrait des différences entre les effets d'un schéma posologique de méropénème avec administration d'une faible dose à intervalle réduit ( $500 \mathrm{mg}$ toutes les 6 heures) et d'une posologie traditionnelle (1000 mg toutes les 8 heures) pour ce qui est des résultats cliniques et des coûts pour le système de santé.

Méthodes : La présente étude de cohorte rétrospective incluait 194 patients ayant reçu le méropénème selon le schéma posologique traditionnel (entre juillet 2006 et août 2008) et 188 patients l'ayant reçu avec administration d'une faible dose à intervalle réduit (entre décembre 2008 et octobre 2009) dans un grand hôpital de soins tertiaires et un hôpital communautaire. Le principal paramètre d'évaluation (succès clinique), les paramètres d'évaluation secondaires (taux de mortalité à l'hôpital dans les 30 jours, période de défervescence, durée du traitement et durée du séjour) et les coûts des médicaments ont été comparés entre les cohortes.

Résultats : Les deux cohortes n'étaient pas significativement différentes en ce qui touche aux caractéristiques de base. Il n'y avait aucune différence statistiquement significative entre le schéma posologique avec administration d'une faible dose à intervalle réduit et la posologie traditionnelle en ce qui concerne le principal paramètre d'évaluation : le succès clinique a été obtenu respectivement chez $83,5 \%(162 / 194)$ et chez $80,8 \%(152 / 188)$ des patients. De même, aucune différence statistiquement significative n'a été relevée pour les paramètres d'évaluation secondaires. Par contre, le coût moyen des médicaments par patient par visite était de 222,23 \$ pour le schéma posologique avec administration d'une faible dose à intervalle réduit et de 355,90 \$ pour la posologie traditionnelle, une différence significative de plus de $130 \$$ par patient par visite $(p<0,001)$.

Conclusion : Le schéma posologique de méropénème avec administration d'une faible dose à intervalle réduit produisait des résultats cliniques semblables à ceux de le posologie traditionnelle, et ce, pour un prix significativement plus faible.

Mots clés : méropénème, pharmacodynamie, gestion responsable, posologie, résultats 


\section{INTRODUCTION}

$\mathrm{M}$ eropenem is a broad-spectrum parenteral carbapenem antibiotic that is active against most gram-positive and gram-negative bacteria. ${ }^{1}$ Given its broad spectrum of activity, it is often reserved for more complicated bacterial infections. Like other ß-lactam antibiotics, meropenem exerts time-dependent bactericidal activity that is maximized by optimizing the time when free drug concentration exceeds the minimum inhibitory concentration (MIC) for a given pathogen $\left(\% \mathrm{fT}_{>\mathrm{MIC}}\right) .{ }^{1,2}$ The commonly cited range of $\% \mathrm{f}_{>\mathrm{MIC}}$ for meropenem is $20 \%-$ $40 \%$, although it appears to be based on minimal scientific investigation. ${ }^{2}$ The traditional meropenem dosage is $1000 \mathrm{mg}$ every $8 \mathrm{~h}$. Alternative regimens that have been tried involve prolonged infusion times or a small-dose, short-interval approach, with the goal of achieving similar pharmacodynamic targets while minimizing drug cost. ${ }^{2}$ One of the more common alternatives, $500 \mathrm{mg}$ every $6 \mathrm{~h}$, has shown equivalency in terms of \%f $\mathrm{T}_{>\mathrm{MIC}}$ in 4 separate Monte Carlo simulation studies ${ }^{3-6}$ and also in a recent systematic review. ${ }^{2}$

Three previous retrospective studies have compared the clinical efficacy and cost savings of the small-dose, short-interval meropenem dosing regimen ( $500 \mathrm{mg}$ every $6 \mathrm{~h}$ ) with those of the traditional regimen. ${ }^{7-9}$ Patel and others ${ }^{7}$ reviewed the charts of 192 patients who received the small-dose, short-interval regimen and 100 patients who received the traditional regimen and found similar mortality rates $(11.5 \%$ and $8 \%$, respectively), clinical success rates $(92.1 \%$ and $90.1 \%$, respectively), and median durations of meropenem therapy ( 4 and 5 days, respectively). However, there was a statistically significant reduction in the median time to resolution of infection with the small-dose, shortinterval regimen (1.5 and 3 days, respectively; $p<0.0001){ }^{7}$ Kotapati and others ${ }^{8}$ conducted a chart review for 45 patients who received small-dose, short-interval dosing and 40 patients who received traditional dosing, finding no difference in meropenemrelated length of stay ( 7 and 7.5 days, respectively), clinical success rates $(78 \%$ and $82 \%$, respectively), microbiological eradication rates (63\% and $79 \%$, respectively), or median time to resolution of infection ( 4 and 4.5 days, respectively). Finally, in a retrospective analysis, Arnold and others ${ }^{9}$ found no statistically significant differences in time to defervescence ( 2 and 3 days, respectively), need for additional antibiotics (17\% and $14 \%$, respectively), treatment duration (8 days for both groups), or in-hospital mortality (7\% for both groups). Drug cost savings with the small-dose, short-interval regimen were substantial across all studies, ranging from US\$151 to US\$406 saved per patient per visit. $^{7-9}$

Given the available evidence on alternative dosing of meropenem, the Fraser Health Authority Infectious Diseases Subcommittee introduced new guidelines for this drug in October 2008, recommending that clinicians adopt the standardized smalldose, short-interval regimen (500 mg IV every $6 \mathrm{~h}$ ) for most infections in patients with adequate renal function (estimated glomerular filtration rate $[\mathrm{eGFR}] \geq 50 \mathrm{~mL} / \mathrm{min}) .{ }^{6,7,10}$ Dosage adjustments for patients with reduced renal function $(e G F R<50$ $\mathrm{mL} / \mathrm{min}$ ) were also included. ${ }^{10}$ However, it was recognized that these recommendations were based on small, single-centre studies targeting specific infections and excluding patients with impaired renal function (eGFR $<25 \mathrm{~mL} / \mathrm{min}$ ). Also, the previous cost savings literature was based on the US health care system. The current study was undertaken to build upon the existing evidence by characterizing clinical efficacy in a larger population of patients with a broader spectrum of infections and a broader range of renal function. We also wanted to generate results that would be generalizable to the Canadian health care setting.

The primary objective of this study was to characterize differences in clinical outcomes between the small-dose, shortinterval meropenem dosing regimen of $500 \mathrm{mg}$ every $6 \mathrm{~h}$ and the traditional dosing regimen of $1000 \mathrm{mg}$ every $8 \mathrm{~h}$. Additionally, we examined the potential cost savings that could be achieved by using this small-dose, short-interval approach.

\section{METHODS}

\section{Study Design}

This study was a chart review at a tertiary care hospital and a community hospital. The study was approved by the Fraser Health Research Ethics Board. Informed consent was not required because of the retrospective nature of the study.

\section{Inclusion Criteria}

All patients who received a minimum of $72 \mathrm{~h}$ of traditionally dosed meropenem (1000 mg IV every $8 \mathrm{~h}$ ) were eligible for inclusion in the historical cohort. All patients who received a minimum of $72 \mathrm{~h}$ of the small-dose, short-interval meropenem regimen $(500 \mathrm{mg}$ IV every $6 \mathrm{~h}$ ) were eligible for inclusion in the alternative cohort. The inclusion periods were based on release of the Infectious Diseases Subcommittee guidelines in October 2008, avoiding the 2 months immediately before and after release (to allow for clinician adaptation) and extending long enough to achieve the desired sample size. Adjustment in dosing frequency according to renal function was acceptable if it followed the adjustment recommendations in the guidelines, as outlined in Table 1. These dosage adjustments differed from those of the manufacturer but allowed for adjustment for patients with estimated eGFR below $25 \mathrm{~mL} / \mathrm{min}$. Eligible patients were identified from the prescription database report of the Fraser Health Authority's medication-use evaluation team. From this pool of eligible patients, the required sample population was randomly selected for the analysis through random sequence generation.

\section{Exclusion Criteria}

Patients were excluded if they were younger than 18 years of age, had a body mass index greater than $40 \mathrm{~kg} / \mathrm{m}^{2}$, were receiving 
Table 1. Meropenem Dosage Adjustment According to Estimated Glomerular Filtration Rate (eGFR)

\begin{tabular}{lcccc} 
& \multicolumn{4}{c}{ Meropenem Dosing Regimen by eGFR } \\
\cline { 2 - 5 } Regimen & eGFR $\geq \mathbf{5 0 ~ m L / m i n}$ & eGFR 25-49 mL/min & eGFR 10-24 mL/min & eGFR $<10 \mathrm{~mL} / \mathbf{m i n}$ \\
\hline Traditional* & $1000 \mathrm{mg} \mathrm{IV} \mathrm{q8h}$ & $1000 \mathrm{mg} \mathrm{IV} \mathrm{q12h}$ & $1000 \mathrm{mg} \mathrm{IV} \mathrm{q12h}$ & $1000 \mathrm{mg} \mathrm{IV} \mathrm{q24h}$ \\
Small-dose, short-interval & $500 \mathrm{mg} \mathrm{IV} \mathrm{q6h}$ & $500 \mathrm{mg} \mathrm{IV} \mathrm{q8h}$ & $500 \mathrm{mg} \mathrm{IV} \mathrm{q12h}$ & $500 \mathrm{mg} \mathrm{IV} \mathrm{q24h}$ \\
\hline
\end{tabular}

*Traditional dosing regimen adapted from Aronoff and others. ${ }^{10}$

dialysis, or were pregnant. Patients with infections necessitating higher-than-usual meropenem concentrations (primarily cystic fibrosis and meningitis) were also excluded. Those whose antibiotic dose was not adjusted according to renal function within $48 \mathrm{~h}$ were excluded, as were patients with a meropenem dosing regimen other than the traditional regimen or the small-dose, short-interval regimen, as described in Table 1. Patients with solitary infections (i.e., having a single source, such as isolated pneumonia or urinary tract infection) caused by a meropenemresistant organism confirmed by culture and susceptibility testing were excluded.

\section{Data Collection}

Baseline clinical and demographic characteristics, microbiological data, and meropenem dosing information were collected from the charts selected for review. Clinical data, including temperature, leukocyte count, neutrophil count, and any relevant notation within the progress notes pertaining to the patient's infection, were also recorded for comparison between cohorts. The data were collected by one investigator (C.C.) using both electronic and paper-based medical records.

The primary efficacy end point, clinical success rate, was defined as the percentage of patients with elevation of peripheral temperature $\left(>37.5^{\circ} \mathrm{C}\right)$, leukocyte count $\left(>11 \times 10^{\circ} / \mathrm{L}\right)$, and $/$ or neutrophil count $\left(>8 \times 10^{9} / \mathrm{L}\right)$ at initiation of meropenem who experienced normalization of or reduction from baseline in temperature (normally $\leq 37.5^{\circ} \mathrm{C}$ ), leukocyte count (normally $\leq 11 \times 10^{9} / \mathrm{L}$ ), and neutrophil count (normally $\leq 8 \times 10^{9} / \mathrm{L}$ ) along with signs of clinical resolution or improvement as noted in the patient chart. Clinical success could be either complete (i.e., total improvement within the duration of meropenem therapy) or partial (i.e., a trend in improvement, defined as consecutive values for temperature, leukocyte count, or neutrophil count decreasing toward normal, with de-escalation or discontinuation of antibiotics before full resolution). The secondary efficacy outcomes were in-hospital mortality, meropenem-related length of stay, duration of meropenem therapy, and time to defervescence. In-hospital mortality was defined as patient death during the admission in which meropenem was administered. Mortality was further stratified as infection-related and non-infection-related on the basis of clinician notes; if the cause of death was not specified, it was conservatively assumed that the death was related to an infectious process. Meropenem-related length of stay was defined as the length of time from initiation of meropenem therapy to discharge. Time to defervescence, captured only for those with elevated temperature at the start of meropenem therapy, was measured as the time from meropenem initiation to the point of normal body temperature, defined as consecutive temperatures below or equal to $37.5^{\circ} \mathrm{C}$. Any discrepancies or ambiguities were discussed among the 3 investigators until a general consensus was reached.

Subgroup analysis was performed for more acutely ill populations, specifically patients admitted to the intensive care unit (ICU) and patients with Pseudomonas aeruginosa infections.

A historical cost analysis was conducted to determine whether there were any actual savings between 2006 and 2009. In addition, because there was a transition to use of generic meropenem in 2012 within the health authority, a prorated cost analysis was also conducted using meropenem pricing as of April 2015. For both the historical and current-pricing comparisons, the costs were determined by multiplying the total number of doses received by patients in the study by the cost per dose.

\section{Statistical Analysis}

Given the decreased time to infection resolution with the small-dose, short-interval meropenem dosing regimen observed by Patel and others ${ }^{7}$ in what was, at the time of study inception, the largest clinical investigation published to date, we used a superiority study design. Using the clinical cure rate in that trial, with a small predicted difference in effect size and $\alpha=0.05$, we determined that 186 patients were needed in each cohort for $80 \%$ statistical power. Based on an estimated 33\% exclusion rate, 250 patients were randomly selected per cohort. All categorical data (baseline demographic characteristics and outcomes) were analyzed using $\chi^{2}$ analysis or the Fisher exact test; continuous outcomes were compared with either the Student $t$ test or Wilcoxon sum-rank test as appropriate. Differences between the 2 cohorts were adjusted by regression analysis as appropriate. Statistical significance included any 2-sided $p$ value less than or equal to 0.05 . All statistical analyses were carried out using Microsoft Excel 2010 (Microsoft Corp, Redmond, Washington). Data collection, statistical analysis, and manuscript creation were conducted without any financial support or corporate input.

\section{RESULTS}

To obtain the required sample size for the historical cohort, we included patients who received a minimum of $72 \mathrm{~h}$ of traditionally dosed meropenem from July 16, 2006, to August 
16, 2008. To obtain the required sample size for the alternative cohort, we included patients who received a minimum of $72 \mathrm{~h}$ of the small-dose, short-interval meropenem regimen from December 16, 2008, to October 16, 2009.

After application of the exclusion criteria, the cohort with traditional dosing of meropenem had 194 patients and the cohort with small-dose, short-interval dosing had 188 patients (Figure $1)$. Both the reasons for exclusion and the numbers of patients excluded were similar between groups. No statistically significant differences were found between cohorts in terms of baseline characteristics or frequency of comorbidities (Table 2). Likewise, microbiological isolates and concomitant antibiotic usage were similar between groups (Table 3). The only statistically significant difference was related to the source of infection, there being more urinary tract infections in the small-dose, short-interval cohort (37.8\% versus $27.3 \%$; $p=0.04)$.

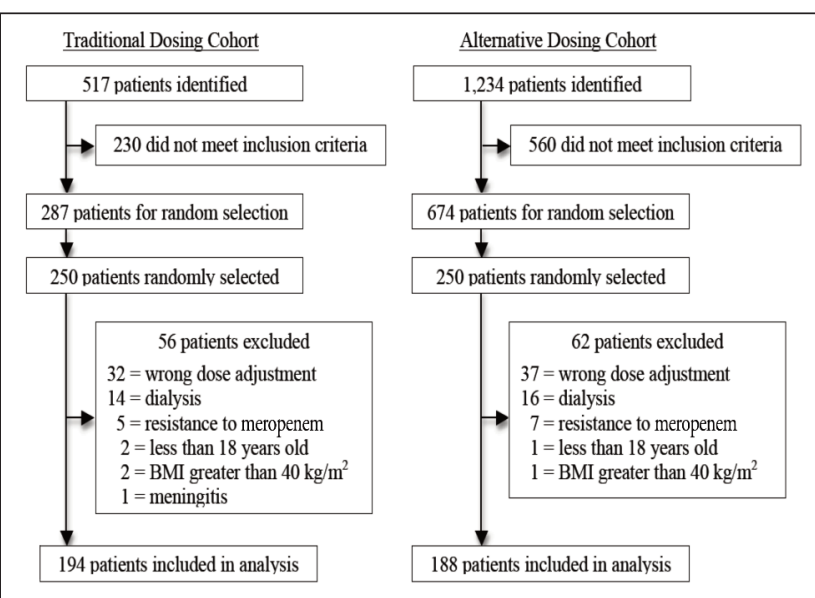

Figure 1. Study flow chart. BMI = body mass index.

Table 2. Baseline Characteristics of Patients Who Received Traditional
or Small-Dose, Short-Interval Dosing of Meropenem

\begin{tabular}{|c|c|c|}
\hline \multirow[b]{2}{*}{ Characteristic } & \multicolumn{2}{|c|}{$\begin{array}{c}\text { Dosing Regimen*; } \\
\text { Mean } \pm \text { SD or No. (\%) of Patientst }\end{array}$} \\
\hline & $\begin{array}{l}\text { Traditional Dosing } \\
(n=194)\end{array}$ & $\begin{array}{c}\text { Small-Dose, Short-Interval } \\
\text { Dosing }(n=188)\end{array}$ \\
\hline Age (years) & $64.9 \pm 14.5$ & $66.1 \pm 17.3$ \\
\hline Weight (kg) & $73.4 \pm 25.3$ & $72.8 \pm 18.7$ \\
\hline Height (m) & $1.66 \pm 0.1$ & $1.67 \pm 0.1$ \\
\hline BMI $\left(\mathrm{kg} / \mathrm{m}^{2}\right)$ & $24.4 \pm 5.1$ & $25.1 \pm 5.2$ \\
\hline Sex, male & $99(51.0)$ & $96(51.1)$ \\
\hline Length of stay (days) & $11.6 \pm 31.1$ & $10.9 \pm 25.1$ \\
\hline eGFR (mL/min) & $67.6 \pm 30.0$ & $68.4 \pm 33.0$ \\
\hline$\geq 50 \mathrm{~mL} / \mathrm{min}$ & $147(75.8)$ & $128(68.1)$ \\
\hline $25-49 \mathrm{~mL} / \mathrm{min}$ & $31(16.0)$ & $44(23.4)$ \\
\hline $10-24 \mathrm{~mL} / \mathrm{min}$ & $13 \quad(6.7)$ & $16 \quad(8.5)$ \\
\hline$<10 \mathrm{~mL} / \mathrm{min}$ & $3 \quad(1.5)$ & $0 \quad(0.0)$ \\
\hline ICU admission & $19 \quad(9.8)$ & $23(12.2)$ \\
\hline \multicolumn{3}{|l|}{ Comorbidity } \\
\hline Hypertension & $78(40.2)$ & 92 (48.9) \\
\hline Diabetes mellitus & $55(28.4)$ & $59(31.4)$ \\
\hline Coronary artery disease & $42(21.6)$ & $42(22.3)$ \\
\hline Congestive heart failure & $24(12.4)$ & $32(17.0)$ \\
\hline Cerebrovascular disease & $20(10.3)$ & $22(11.7)$ \\
\hline Cancer & 71 (36.6) & $57(30.3)$ \\
\hline Lung disease & $38(19.6)$ & $38(20.2)$ \\
\hline Liver disease & $20(10.3)$ & $19(10.1)$ \\
\hline Kidney disease & $31(16.0)$ & $34(18.1)$ \\
\hline $\begin{array}{l}\text { Neutropenia } \\
\text { (ANC }<1000 \text { cells/ } \mu \mathrm{L} \text { ) }\end{array}$ & $16 \quad(8.2)$ & $9 \quad(4.8)$ \\
\hline Immunodeficiency & $3 \quad(1.5)$ & $5 \quad(2.7)$ \\
\hline Auto-inflammatory disease & $10 \quad(5.2)$ & $8 \quad(4.3)$ \\
\hline Concomitant antibiotics & $96(49.5)$ & 87 (46.3) \\
\hline Metronidazole & $29(14.9)$ & $23(12.2)$ \\
\hline Vancomycin & $33(17.0)$ & $34(18.1)$ \\
\hline Fluoroquinolone & $26(13.4)$ & $32(17.0)$ \\
\hline Other & $23(11.9)$ & $27 \quad(14.4)$ \\
\hline
\end{tabular}

$\overline{\mathrm{ANC}}=$ absolute neutrophil count, $\mathrm{BMl}=$ body mass index,

eGFR = estimated glomerular filtration rate, ICU = intensive care unit

*Traditional $=1000 \mathrm{mg} \mathrm{IV} \mathrm{q8h}$; small-dose, short-interval = $500 \mathrm{mg} \mathrm{IV} \mathrm{q6h.}$

tFor all characteristics, $p>0.05$. 
Table 3. Source of Infection and Bacteria Identified for Patients Who Received Traditional or Small-Dose, Short-Interval Dosing of Meropenem

\begin{tabular}{|c|c|c|}
\hline \multirow[b]{2}{*}{ Characteristic of Infection } & \multicolumn{2}{|c|}{ Dosing Regimen*; No. (\%) of Patients } \\
\hline & $\begin{array}{l}\text { Traditional Dosing } \\
(n=194)\end{array}$ & $\begin{array}{c}\text { Small-Dose, Short-Interva } \\
\text { Dosing }(n=188)\end{array}$ \\
\hline Microbial source & & \\
\hline Blood & $76(39.2)$ & $70(37.2)$ \\
\hline Abdomen & $50(25.8)$ & $42(22.3)$ \\
\hline Urinary tract $†$ & $53(27.3)$ & $71(37.8)$ \\
\hline Skin and soft tissue & 19 (9.8) & $11 \quad(5.9)$ \\
\hline Lung & $76(39.2)$ & $71(37.8)$ \\
\hline Stool & $5 \quad(2.6)$ & $3(1.6)$ \\
\hline Bone and connective tissue & $2(1.0)$ & $0 \quad(0.0)$ \\
\hline Multiple & $70(36.1)$ & $64(34.0)$ \\
\hline \multicolumn{3}{|l|}{ Microbial isolates } \\
\hline Escherichia coli & $35(18.0)$ & $43(22.9)$ \\
\hline Enterococcus spp. & $13(6.7)$ & $17 \quad(9.0)$ \\
\hline $\begin{array}{l}\text { Multidrug-susceptible } \\
\text { Staphylococcus aureus }\end{array}$ & $12 \quad(6.2)$ & $7 \quad(3.7)$ \\
\hline Pseudomonas aeruginosa & $10 \quad(5.2)$ & $15 \quad(8.0)$ \\
\hline $\begin{array}{l}\text { SPICE organisms (Serratia spp., } \\
\text { Providencia spp., Morganella spp., } \\
\text { Citrobacter spp., Enterobacter spp., } \\
\text { Proteus vulgaris) }\end{array}$ & $9 \quad(4.6)$ & $7 \quad(3.7)$ \\
\hline Klebsiella spp. & $4 \quad(2.1)$ & $3(1.6)$ \\
\hline Proteus mirabilis & $4 \quad(2.1)$ & $2(1.1)$ \\
\hline Corynebacterium spp. & $4 \quad(2.1)$ & $2(1.1)$ \\
\hline Viridans group Streptococcus & $3(1.5)$ & $0 \quad(0.0)$ \\
\hline Group B Streptococcus & $2 \quad(1.0)$ & $4 \quad(2.1)$ \\
\hline $\begin{array}{l}\text { Multidrug-resistant } \\
\text { Staphylococcus aureus }\end{array}$ & $2 \quad(1.0)$ & $4 \quad(2.1)$ \\
\hline Acinetobacter spp. & $1 \quad(0.5)$ & $4 \quad(2.1)$ \\
\hline Streptococcus pneumoniae & $1 \quad(0.5)$ & $1 \quad(0.5)$ \\
\hline Anaerobes & $2 \quad(1.0)$ & $5 \quad(2.7)$ \\
\hline Polymicrobial & $22(11.3)$ & $22(11.7)$ \\
\hline
\end{tabular}

In terms of the primary outcome, there was no statistically significant difference in clinical success rate (whether partial or complete) between the traditional dosing regimen and the small-dose, short-interval dosing regimen $(83.5 \%$ versus $80.8 \%$; $p=0.51$ ). In addition, no differences were identified between the traditional dosing regimen and the small-dose, short-interval dosing regimen in terms of proportion of patients with complete clinical success (Table 4). A subgroup comparison involving patients admitted to the intensive care unit (ICU) showed no difference in the primary outcome of clinical success between the traditional and the small-dose, short-interval regimen. Similarly, there was no between-group difference in success rate for patients with $P$. aeruginosa infection (Table 5). Finally, no significant differences were identified in any of the secondary clinical outcomes, specifically mortality, duration of therapy, meropenemrelated length of stay, and time to defervescence (Table 6).

The cost analysis revealed a statistically significant difference in drug cost per patient per visit in favour of the small-dose, short-interval regimen. Historically, the mean cost per patient per visit was $\$ 1016.97$ for the traditional regimen and $\$ 627.21$ for the small-dose, short-interval regimen. Using costs prorated to April 2015, the mean cost per patient per visit was $\$ 355.90$ for the traditional regimen and $\$ 222.23$ for the small-dose, shortinterval regimen $(\mathrm{p}<0.001)$. The overall savings with the smalldose, short-interval regimen were \$79 417.44 and \$27 279.48 with historical and current pricing, respectively.

\section{DISCUSSION}

At a time when increasing demand on the health care system puts increased strain on health care budgets, practice innovations must be instituted to minimize costs. Use of a small-dose, shortinterval dosing regimen for meropenem represents an effort to incorporate pharmacodynamic properties into decision-making, with the objective of decreasing drug costs. Data showing similar 


\section{Table 4. Clinical Success for Patients Who Received Traditional or Small-Dose, Short-Interval Dosing of Meropenem}

\begin{tabular}{|c|c|c|c|}
\hline \multirow[b]{2}{*}{ Category of Success } & \multicolumn{2}{|c|}{ Dosing Regimen*; No. (\%) of Patients } & \multirow[b]{2}{*}{$\operatorname{RR}(95 \% \mathrm{Cl})$} \\
\hline & $\begin{array}{l}\text { Traditional Dosing } \\
(n=194)\end{array}$ & $\begin{array}{c}\text { Small-Dose, Short-Interval } \\
\text { Dosing }(n=188)\end{array}$ & \\
\hline $\begin{array}{l}\text { Clinical success } \\
\text { (partial or complete) } \dagger\end{array}$ & $162(83.5)$ & $152(80.8)$ & $0.97(0.88-1.07)$ \\
\hline Complete success only $\ddagger$ & $102(52.6)$ & $94(50.0)$ & $0.95(0.77-1.17)$ \\
\hline \multicolumn{4}{|c|}{$\begin{array}{l}\mathrm{Cl}=\text { confidence interval, RR = relative risk. } \\
\text { *Traditional = } 1000 \mathrm{mg} \text { IV q8h; small-dose, short-interval = } 500 \mathrm{mg} \text { IV q6h. } \\
\text { tData for patients with either complete or partial clinical success. The complete clinical success rate was defined on } \\
\text { the basis of normalization of peripheral temperature (to } \leq 37.5^{\circ} \mathrm{C} \text { ), leukocyte count (to } \leq 11 \times 10^{9} / \mathrm{L} \text { ), and/or } \\
\text { neutrophil count (to } \leq 8 \times 10^{9} / \mathrm{L} \text { ), along with signs of clinical resolution as noted in the patient chart. Clinical success } \\
\text { was deemed not to have been achieved if the patient died during the admission or if therapy was stopped because } \\
\text { of a serious adverse event. The partial clinical success rate was defined on the basis of reduction in temperature, } \\
\text { leukocyte count, and neutrophil count from initially elevated values (but without full resolution), along with signs } \\
\text { of clinical improvement from baseline as noted in patient chart. For further detail, please see Methods, under } \\
\text { "Data Collection". } \\
\text { fExcludes patients with partial success. }\end{array}$} \\
\hline
\end{tabular}

Table 5. Subgroup Analyses of Clinical Success for Patients Who Received Traditional
or Small-Dose, Short-Interval Dosing of Meropenem

\begin{tabular}{|c|c|c|c|}
\hline \multirow[b]{2}{*}{ Subgroup } & \multicolumn{2}{|c|}{ Dosing Regimen*; No. (\%) of Patients } & \multirow[b]{2}{*}{$\operatorname{RR}(95 \% \mathrm{Cl})$} \\
\hline & Traditional Dosing & $\begin{array}{c}\text { Small-Dose, } \\
\text { Short-Interval Dosing }\end{array}$ & \\
\hline Patients in the ICU & $15 / 19(79)$ & $15 / 23(65)$ & $0.83(0.59-1.29)$ \\
\hline $\begin{array}{l}\text { Patients with Pseudomonas } \\
\text { aeruqinosa infection }\end{array}$ & $9 / 10(90)$ & $11 / 15(73)$ & $0.82(0.67-1.33)$ \\
\hline
\end{tabular}

\section{Table 6. Secondary Outcomes among Patients Who Received Traditional or Small-Dose, Short-Interval Dosing of Meropenem}

\begin{tabular}{|c|c|c|c|}
\hline \multirow[b]{2}{*}{ Outcome } & \multicolumn{2}{|c|}{$\begin{array}{l}\text { Dosing Regimen*; } \\
\text { No. (\%) of Patients or Mean Value }\end{array}$} & \multirow[b]{2}{*}{$p$ Value } \\
\hline & $\begin{array}{l}\text { Traditional Dosing } \\
(n=194)\end{array}$ & $\begin{array}{c}\text { Small-Dose, Short- } \\
\text { Interval Dosing }(n=188)\end{array}$ & \\
\hline 30 day all-cause mortality & $18(9.2)$ & $27(14.4)$ & 0.15 \\
\hline $\begin{array}{l}30 \text { day infection-related } \\
\text { mortality }\end{array}$ & $9(4.6)$ & $12 \quad(6.4)$ & 0.51 \\
\hline $\begin{array}{l}\text { Duration of meropenem } \\
\text { therapy (days) }\end{array}$ & 6.9 & 6.9 & 0.93 \\
\hline $\begin{array}{l}\text { Meropenem-related length } \\
\text { of stay (days) }\end{array}$ & 24.5 & 27.8 & 0.27 \\
\hline Time to defervescence (days) & 2.2 & 2.1 & 0.62 \\
\hline
\end{tabular}

$\% \mathrm{f}_{>\mathrm{MIC}}$ between traditional and small-dose, short-interval meropenem dosing regimens suggest that clinical effects should be similar even with the administration of 33\% less medication over a 24-h period with the latter approach. Accordingly, the handful of studies ${ }^{7-9}$ examining clinical outcomes of alternative dosing strategies have suggested, at a minimum, equivalence in outcomes such as clinical cure rate and mortality, with possible superiority in terms of time to resolution of the infection. ${ }^{7} \mathrm{We}$ used a superiority trial design based on the observed decrease in time to infection resolution to determine whether there was a similar advantage in terms of clinical success rate with the small- dose, short-interval dosing regimen relative to traditional dosing. Our objective was to build upon existing evidence while broadening applicability. One aspect of our approach was to remove limitations of renal function as an exclusion criterion; by incorporating patients with any eGFR, provided they were not receiving dialysis, we were able to capture a more critically ill population, who might be more likely to receive meropenem therapy. Whereas previous studies excluded patients who were afebrile throughout their antibiotic therapy and patients with neutropenia, we included patients without fever, as well as those with febrile neutropenia, using a collection of clinical signs and 
symptoms and laboratory values to determine whether clinical success was achieved. ${ }^{7-9}$ The intention was to encompass as broad a patient population as possible for maximal applicability to practice.

This study had clinical success rates in keeping with the previous investigation by Kotapati and others, ${ }^{8}$ but lower than those found in a larger study by Patel and others. ${ }^{7}$ Inclusion in the current study of patients with more severe renal dysfunction and a greater proportion of patients with malignancy may have been factors contributing to the lower success rate reported here. We also chose a conservative threshold for elevated peripheral temperature $\left(>37.5^{\circ} \mathrm{C}\right)$ on the basis of previous febrile neutropenia studies, ${ }^{11,12}$ not accounting for circadian differences and differences in location of temperature readings. However, we did not identify superiority of the small-dose, short-interval dosing regimen in terms of the primary outcome. Findings of no significant difference in length of stay and in-hospital mortality were also consistent with previous studies; however, in contrast with observations by Patel and others, ${ }^{7}$ we found no decrease in time to defervescence. Of note, there was a trend toward a higher mortality rate with the small-dose, short-interval regimen $(14.4 \%$ versus $9.2 \%, p=0.15)$ : however, when mortality was stratified by its relation to infection, the rates were similar between the 2 regimens (Table 6). Indeed, in the small-dose, short-interval group, a greater proportion of the mortality rate was related to malignancy than to meropenem failure. Given that mortality was a secondary end point, additional studies with sufficient statistical power are needed to confirm the results.

The purpose of examining the ICU subgroup was to quantify the effect of administering less drug overall in a more acutely ill population. Likewise, we analyzed the subgroup of patients with $P$. aeruginosa infections to determine whether there was any difference in clinical effect according to the regimen used. Both subgroup analyses showed no difference in clinical success rate between dosing regimens, although the numbers of patients within these subgroups were small relative to the entire study population (i.e., $42 \mathrm{ICU}$ patients and 25 patients infected with P. aeruginosa out of 382 patients in the study as a whole), and the subgroup analyses were not powered to detect a difference. Additional studies of sufficient statistical power are needed to assess the critically ill population and those infected with more virulent organisms.

With the secondary cost analysis, we hoped to quantify potential cost savings in terms of Canadian dollars, given that previous pharmacoeconomic analyses were done in the United States. Similar to previous studies, we found significant cost savings with use of the small-dose, short-interval regimen. Given that mean treatment duration was similar for the 2 cohorts (6.9 days for both), the cost savings can be attributed to the use of $33 \%$ less meropenem per day with the small-dose, short-interval regimen. In recognition of the substantial cost difference between brand and generic medication, we conservatively prorated costs to April 2015 in the current-pricing comparison. Cost savings were notable in terms of both prorated and historical pricing, although the magnitude of savings was substantially less when the conservative estimate was used (\$27 279.48 versus \$79 417.44).

This investigation had some limitations. First, the retrospective nature of the study likely introduced unavoidable confounders that may have affected the results. However, by maximizing the sample size and randomly selecting the patient population, we were able to obtain 2 cohorts with similar baseline characteristics (most notably in terms of comorbidities and renal function). The only patient characteristic that differed significantly, the presence of a urinary infection, did not affect the statistical results when examined by regression analysis.

In addition, the superiority design of the study inhibited our ability to conclude clinical equivalence between the 2 dosing regimens. An ideal study would use a non-inferiority design, but such a trial would require tens of thousands of patients, given the high clinical success rate and the minimal difference in outcomes between dosing regimens. Given the sporadic use of meropenem before emergence of extended-spectrum ß-lactamase organisms, it would have been difficult to obtain sufficient patients eligible for inclusion in the study. The inclusion time period for the traditional dosing cohort reflected this lack of patients, in that we had to use 2 years of data for this cohort but only 1 year of data for the small-dose, short-interval cohort (2006-2008 versus 2008-2009). Further broadening of the inclusion period would have introduced temporal confounders such as changes in practice standards that would have affected the clinical outcomes. Despite this limitation, we feel that these results, in combination with a growing body of evidence suggesting similar clinical success rates in other settings, will allow decision-makers to more confidently assume clinical equivalence between these dosing regimens.

This study did not include a safety comparison between the dosing regimens. However, we examined 2 dosing regimens of the same medication (which were shown to exhibit similar pharmacokinetic and pharmacodynamics parameters), so we felt that such an investigation would likely not have added value to these results.

As is the case for other studies in the infectious disease literature, there was inter-clinician variability in the primary outcome of clinical success (e.g., radiographic improvement, decrease in symptoms). To minimize this variability, we took a conservative approach: in the absence of data from physician progress notes and in the absence of objective outcomes such as defervescence or leukocyte count, we assumed clinical failure.

Finally, the cost analysis was restricted to drug cost alone and did not incorporate material costs (e.g., tubing, IV bags), dispensary preparation time, or nursing administration factors. It might be argued that use of broad-spectrum antibiotics such as meropenem may be curtailed by initiatives such as antimicrobial stewardship 
and that drug cost alone is not sufficient to determine overall savings. Future in-depth pharmacoeconomic studies may be required to further delineate the actual cost savings that can be realized with a small-dose, short-interval meropenem dosing regimen based on current practices.

\section{CONCLUSION}

To our knowledge, this study is the largest to date comparing the clinical effects of a small-dose, short-interval meropenem dosing regimen with the traditional dosing regimen, and the only one to include patients with all stages of renal dysfunction. The investigation did not reveal any statistically significant differences in clinical efficacy outcomes: therefore, we conclude that meropenem $500 \mathrm{mg}$ every $6 \mathrm{~h}$ is not superior to meropenem 1000 $\mathrm{mg}$ every $8 \mathrm{~h}$. However, use of the small-dose, short-interval dosing regimen was associated with significant drug cost savings (more than Can $\$ 130$ per patient per visit). This pharmacoeconomic advantage and the lack of evidence to suggest worse patient outcomes indicate that the small-dose, short-interval regimen could be adopted system-wide. Further studies are needed to confirm these results, especially in-depth pharmacoeconomic studies to delineate overall cost savings.

\section{References}

1. Merrem [product monograph]. In: Repchinsky C, editor-in-chief. $e$-CPS. Ottawa (ON): Canadian Pharmacists Association; 2012 [cited 2013 Jun 22]. Available from: https://www-e-therapeutics-ca. Subscription required to access content.

2. Perrott J, Mabasa VH, Ensom MHH. Comparing outcomes of meropenem administration strategies based on pharmacokinetic and pharmacodynamic principles: a qualitative systematic review. Ann Pharmacother. 2010;44(3): 557-64.

3. Lomaestro BM, Drusano GL. Pharmacodynamic evaluation of extending the administration time of meropenem using a Monte Carlo simulation. Antimicrob Agents Chemother. 2005;49(1):461-3.

4. Wang H, Zhang B, Ni Y, Kuti JL, Chen B, Chen M, et al. Pharmacodynamic target attainment of seven antimicrobials against gram-negative bacteria collected from China in 2003 and 2004. Int J Antimicrob Agents. 2007; 30(5):452-7.

5. Zelenitsky S, Zvonar R, Ariano R. Monte Carlo simulations (MCSs) of meropenem in patients with varying degrees of renal function [abstract]. Can J Hosp Pharm. 2009;62(1):68.
6. Kuti JL, Maglio D, Nightingale CH, Nicolau DP. Economic benefit of a meropenem dosage strategy based on pharmacodynamic concepts. Am J Heatlh Syst Pharm. 2003;60(6):565-8.

7. Patel GW, Duquaine SM, McKinnon PS. Clinical outcomes and cost minimization with an alternative dosing regimen for meropenem in a community hospital. Pharmacotherapy. 2007;27(12):1637-43.

8. Kotapati S, Nicolau DP, Nightingale CH, Kuti JL. Clinical and economic benefits of a meropenem dosage strategy based on pharmacodynamic concepts. Am J Health Syst Pharm. 2004;61(12):1264-70.

9. Arnold HM, McKinnon PS, Augustin KM, Hladnik LM, Casabar E, Reichley RM, et al. Assessment of an alternative meropenem dosing strategy compared with imipenem-cilastatin or traditional meropenem dosing after cefepime failure or intolerance in adults with neutropenic fever. Pharmacotherapy. 2009;29(8):914-23.

10. Aronoff GR, Berns JS, Brier ME, Golpher TA, Morrison G, Singer I, et al., editors. Drug prescribing in renal failure: dosing guidelines for adults. 4th ed. Philadelphia (PA): American College of Physicians; 1999.

11. Fehér C, Rovira M, Soriano A, Esteve J, Martínez JA, Marco F, et al. Effect of meropenem administraton in extended infusion on the clinical outcome of febrile neutropenia: a retrospective observational study. J Antimicrob Chemother. 2014;69(9):2556-62.

12. Tamura K, Matsuoka H, Tsukada J, Masuda M, Ikeda S, Matsuishi E, et al. Cefepime or carbapenem treatment for febrile neutropenia as a single agent is as effective as a combination of 4 th generation cephalosporin + aminoglycosides: comparative study. Am J Hematol. 2002;71(4):248-55.

Ivy Chow, BSC(Pharm), ACPR, PharmD, is a Clinical Pharmacy Specialist with Burnaby Hospital, Burnaby, British Columbia.

Vincent Mabasa, BSc(Pharm), ACPR, PharmD, is Clinical Coordinator at Burnaby Hospital, Burnaby, British Columbia.

Connor Chan, BSc(Pharm), ACPR, is a Clinical Pharmacist at Vancouver General Hospital, Vancouver, British Columbia.

Competing interests: None declared.

Address correspondence to:

Dr Ivy Chow

Burnaby Hospital

3935 Kincaid Street

Burnaby BC V5G 2X6

e-mail: ivy.chow@fraserhealth.ca

Funding: None received. 